\title{
Interrupted Systems Mitigating Social Gender Roles: A Qualitative Inquiry of Motherscholars During a Pandemic
}

\author{
Christine Platt ${ }^{1}$ \\ University of Arizona, USA \\ Melissa Goates-Jones \\ Brigham Young University, USA \\ Ramona Maile Cutri \\ Brigham Young University, USA \\ Louise Wheeler \\ Brigham Young University, USA \\ Tamara Walden \\ University of Central Florida, USA
}

\begin{abstract}
A qualitative reflexive narrative methodology was employed to examine factors that constructed and constrained the experiences of working women academics who were quarantined with their children full-time during the COVID-19 pandemic. Twenty-four motherscholars responded to a computer-based survey with open-ended questions encouraging participants to share their unique stories. Purposive and convenience sampling was employed to obtain a diverse and representative sampling of women that included marginalized groups such as women of color and women who self-identify as members of the Lesbian, Gay, Bisexual, Transgender, Queer/Questioning and all other people (LGBTQ+) associated with this community. Key themes identified include division of labor, self-care, privilege, socialized gender roles, feelings about partners, boundaries, safety, parenting, privacy, and impact on career/productivity. Focusing on participants' personal experiences of privilege or lack thereof, and the interruption of established systems, provided greater insight into how socialized gender roles are intensified during pandemic conditions. When established systems were interrupted, participants were more fully exposed to the negative impacts of socialized gender roles. Support structures motherscholars rely upon are fragile, particularly in times of crisis, which is when they are needed most. Institutions should recognize the hardships incurred during the pandemic and consider adjustments to performance expectations. Future research is needed to determine how best to create stronger structures during times of instability.
\end{abstract}

KEYWORDS: motherhood; socialized gender roles; social privileges; COVID-19 pandemic.

\footnotetext{
${ }^{1}$ Corresponding Author: A doctoral candidate in College of Nursing at the University of Arizona.

E-Mail: crplatt@email.arizona.edu
} 
The COVID-19 pandemic has catapulted traditional academics into online teaching and working (Arum \& Stevens, 2020; Cutri \& Mena, 2020; Cutri et al., 2020; Garbe et al., 2020, Gülbahar \& Adnan, 2020). Faculty have transitioned, created, and implemented online teaching and provided other services online due to university closures and revised campus offerings (Hechinger \& Lorin, 2020; McMurtrie, 2020). Additionally, the demands of university teaching, services, and citizenship have expanded as the pandemic has profoundly impacted students' mental health and well-being (Zhai \& Du, 2020). Professional demands, of course, take place simultaneously with the pandemic-intensified demands of academics' personal lives. The socialized gendered roles and responsibilities in the personal lives of female faculty impact their professional work (Flaherty, 2020; Oleschuk, 2020). Popular media accounts of faculty balancing the demands of motherhood during the coronavirus pandemic range from the humorous to calls for serious consideration of equity issues involved (Minello, 2020; Viswanath \& Mullins, 2020).

The term motherscholar was first coined by Matias (2011) and expanded upon by Lapayese (2012) to describe the desire to "dismantle patriarchal binaries--namely, the sharp divide between the intellect and the maternal, the public and the private" (p. 17). We utilize the term motherscholar in this article as a means of moving beyond a binary approach to analyzing equity issues and out of a commitment to criticality in mothering and scholarship (Matias \& Nishi, 2018). We strive to study the ways in which motherscholars can be both privileged and under-resourced, productive and unproductive, and successful and unsuccessful.

This study examines how the COVID-19 pandemic constricted systems that are vital to motherscholars' ability to both excel in their profession and mother their children. Many motherscholars are aware that it is their privilege that gives them access to these systems. Studying the experiences of scholars who are mothering during the pandemic was not meant to elicit sympathy for their efforts as mothers and academics. Rather, exposing and critiquing the factors that produce and constrain the experiences of these academics mothering during the pandemic provides greater insight into how socialized gender roles are intensified during pandemic conditions. In order to contribute nuanced understandings of the experiences of motherscholars who are full-time mothering and working during the pandemic, we pursued the following research question: What are the factors that produce and constrain the experiences of academics who are quarantined with their children full-time during the COVID-19 pandemic? We first present the conceptual framework informing our inquiry. Second, the methods of research are described. Third, findings and discussion are shared, followed by conclusions about implications and future research.

\section{Conceptual Framework}

Matias and Nishi (2018) explained, "Since the message delivered to women is that motherhood does not mix with scholarly life, women are expected to create a larger separation between the domestic and public/business-worlds" (p. 82). This task was formidable back in 2018. Two years later, in March 2020 as the COVID-19 pandemic unfolded in the U.S., most academics who were mothers had to work from home while quarantined with their children. The burden of creating a larger separation between the domestic and public/business worlds became even more difficult, and the real or perceived request to do so loomed as even more problematic for academics who were mothering during the pandemic.

To establish the conceptual framework informing this study, we use feminist theory to define mothering, distinguish mothering from motherhood, and frame the nature of gendered social norms. Next, we link the institution of motherhood to the institution of academia itself and to the rank and advancement process. Finally, we define social privileges and the systems through which 
they are distributed and consumed as a foundation for discussing how pandemic conditions constrict them and reinforce socialized gender roles.

\section{Mothering, Motherhood, and Gendered Social Roles}

Adrianne Rich (1995) named and claimed mothering as women's lived and told experiences of childbearing and raising. Rich (1995) asserted that mothering was an experience grounded in women-centered creation (literal and figurative) and had the potential to be a location of generative power for women. Rich (1995) argued that this construct of mothering contrasted with the patriarchal dominated institution of motherhood whose history is male-centered and often the location of oppression for women. The ideological institution of motherhood as male-centered and not traditionally empowering to women has persisted even as women have entered the workplace. Bryan (2019) states, "Mothers work. But when and where does their work begin? Where does it end? What constitutes the labor of motherhood and of mothering? What are its boundaries? Who determines those boundaries, and what lies beyond them?" (p. 331). The conditions and restrictions of the COVID-19 pandemic have further blurred the boundaries between work as mothers and work as scholars.

The socialized gender roles assigned to women stem from motherhood as an institution. In her book, Of Women Born: Motherhood as Experience and Institution, Adrienne Rich (1995) argues that motherhood has two meanings that are superimposed upon one another: "the potential relationship of any woman to her powers of reproduction and to children and the institution, which aims at ensuring that that potential--and all women--shall remain under male control" (p. 13). In separating the definition of motherhood into the relational and the obligational, one can understand the different ways in which motherhood is interwoven with traditional female gender roles. For centuries, mothers have been the primary caregivers to their children and have received social and cultural validation for these roles. While mothers may (for the most part) appreciate their relationships with their children, other gender role obligations that are associated with motherhood may interfere with their appreciation of mothering.

By entering the workforce and building careers as scholars, many women have entered the "institutional" realm that has traditionally been enjoyed by men, and thus have rejected the notion that motherhood has to be unidimensional and limiting. Women have found ways to be "good mothers" and also have successful, fulfilling careers through co-parenting, community partnerships, and building flexible workplaces. However, with the onset of the COVID-19 pandemic, the way that women structure their roles as mothers and scholars has been disrupted.

\section{Motherhood and Academia}

Lapayese (2012) emphasizes that Rich's (1995) construct of motherhood operates as “a patriarchal institution to constrain, regulate, and dominate women and their mothering" (p. 1). Like the institution of motherhood, the institution of academia often also operates to advantage men and disadvantage women (Bagilhole \& Goode, 2001). Even when explicit equity policies exist, the inherent culture and systems of advancement benefit the social standing, tendencies, and work of men (Bagilhole \& Goode, 2001; Van den Brink \& Benschop, 2012). For example, Falci \& Watanabe (2020) explained that "faculty women have smaller research and friendship networks than men. Moreover, women are more likely than men to reside on the periphery relative to being in the core of research and friendship networks" (p. 155). Certainly, being quarantined with their children would intensify the already marginalized position of women faculty. 
Van den Brink and Benschop (2012) asserted that academic achievement is inherently gendered. The COVID-19 pandemic has exposed and intensified the gendered nature of academic advancement toward tenure and full professor (Flaherty, 2020; Oleschuk, 2020). What happens when a pandemic and mandated quarantine dictate that home becomes the workplace for academics? This study accessed the lived experiences of women academics working while quarantined with their children at home in order to examine how motherscholars require supportive systems to transcend the constraints and regulations of patriarchal institutions. Examining these systems afforded to women and now interrupted has the potential to uncover ways in which these women extend beyond the binary of either mother or scholar, of home or work.

\section{Privileged Access to Supportive Systems}

In her groundbreaking paper on the connections between white privilege and male privilege, McIntosh (1989) defined privilege as "an invisible package of unearned assets" (p. 1). She described white and male privilege as creating advantages for white people and men that people without these identities do not enjoy. Conversely, the discrimination experienced by Black, Indigenous, and People of Color (BIPOC) and women creates barriers affecting various areas of their lives. Building on McIntosh (1989), other scholars have defined the construct of privilege as 1) unearned social benefits based on dominant group membership; 2) relational in nature; and 3) influenced by intersectionality of identities (Case, 2013; Case et al., 2012). Motherscholars fit into these three facets of privilege in specific ways.

Motherscholars, by employment within the academy, usually have middle class socioeconomic status (SES) (Cooper \& Pugh, 2020). This positionality in the dominant group regarding socioeconomic class grants them access to certain social benefits. Such benefits may include the increased likelihood of residing within a safe neighborhood or children attending safe schools. Support systems available with such positionality, while informal, include neighbors, church groups, sports, and social groups. Improved health and longevity are associated with higher SES (Marmot, 2004). Many factors are intertwined that could affect physical and mental health of motherscholars as well as their ability to balance professional and mothering roles. Self-care amenities such as gyms, entertainment, and private spaces available to middle class women help mitigate socialized gender roles. Built-in childcare at places of work or leisure (e.g., gyms) allows for the co-existence of mothering, professional endeavors, and personal care. Social groups allow women to levy resources in a shared and collective manner such as carpooling kids and providing supplemental activities for children. Formal institutions in the form of public or private schools provide time for professional endeavors without the negative social stigma of leaving a child in the care of another, particularly when the school is considered safe and desirable. Indeed, the benefits of belonging to a middle-class SES come with systems that can support mothering while in academia.

However, research has documented women academics' struggle for equality with their male colleagues in terms of job security, status, and pay (Cardozo, 2017; Coin, 2018; Gonzales, 2018). The motherscholar designation inherently implies involvement in the relational nature of privilege that Case (2013) and Case et al. (2012) emphasize. Motherscholars are in relation with their children, their partners, their former partners, and their professional colleagues. The relational interactions all impact how systems of privilege are afforded to motherscholars and how, during times of crises, these systems can be temporarily or permanently interrupted. For example, being female and having children were both negatively associated with the ability to devote time to research during the pandemic, with the ill effects being cumulative (Myers et al., 2020). The biggest negative impact was for women scholars with young children. 
The loss of childcare, school attendance for children, privacy, and even safe spaces particularly for women of color illustrates how interrupted systems can exacerbate gender inequalities. The intersectional identities of motherscholars are further highlighted when considered within the context of varying sexual orientations, marital status, and race. Case et al. (2012) call for the need to better understand how group privilege operates at the individual level. Focusing on motherscholars' personal experiences of privilege and the interruption of social benefits can lead to recognition of systems through which privilege is distributed, interrupted, or withheld.

\section{Methods}

Here we discuss details of the qualitative reflexive narrative methodology employed to examine factors that constructed and constrained the experiences of working women academics who were quarantined with their children full-time during the COVID-19 pandemic. The following subjects/categories were addressed: Participants, Methodology, and Researchers' Positionality.

\section{Participants}

Participants were 24 academics who are mothers with diverse identities (including LGBTQ+, single mothers, racial/ethnic identities) who were recruited via purposive convenience sampling through personal connections and online social media and networking groups. This nonprobabilistic sampling was specifically employed as a way to ensure inclusion of women that might be missed or excluded with a more traditional sampling technique and, therefore, ensuring that minority voices were heard. Participants were recruited via email and directed to an online survey in which they were asked to give informed consent to participate. Inclusion criteria included individuals who (1) identified as women, (2) were currently raising children in the home, and (3) were involved in academic teaching or research in higher education. Women who agreed to participate completed a brief demographic form and responded to ten open-ended reflexive questions in narrative form. There was no financial incentive to participate.

All participants identified as female and as women $(n=24)$. Diversity was a focus of the sampling technique employed and resulted in 22 of the participants identified as White, two as Black/African American, and one as American Indian or Alaskan Native (participants could select more than one racial identity). Of the 24 participants, three identified as bisexual, one identified as queer, and one identified as unsure or questioning (participants could choose more than one sexual identity). The majority ( $n=23$ ) were married or in a domestic partnership. All participants reported working 40 hours or more per week before the onset of the COVID-19 pandemic, and they held a variety of academic positions (3 Clinical, 1 Visiting Professorial, 2 Adjunct, 14 Tenure/Track (pretenure), 2 Tenured/Associate Professor, 1 Tenured/Full professor). Typical household incomes varied, but 16 participants reported a typical household income of over $\$ 100,000$, and the mean percentage of household income coming from the participant was 59.38\% ( $S D=23.77)$. Participants reported between 3-10 people currently living at home, with a mean of $4.8(S D=3.56)$ people living in the household. See Table 1 for demographics.

\section{Methodology}

We employed a reflexive narrative research methodology and an intimate scholarship frame (Pinnegar \& Hamilton, 2015) to identify and explore the varied experiences of women, including women from traditionally marginalized groups. Narrative research methodology facilitates 
studying experience and knowledge as they are narratively expressed through stories that people live, tell, and relive. Narrative research methodology is inherently relational because it focuses on people's storied existences, and people are intrinsically social (Clandinin \& Murphy, 2009). Narrative research methodology is also always strongly autobiographical (Clandinin \& Connelly, 2000). Narratives are also particularly valuable in qualitative research as they reveal truths about the human experience (Reissman, 2008).

\section{Table 1}

Demographics

Number

(\% out of 24)

Age
$25-34$
$35-44$
$45-54$

Sex

Female

Gender

Woman

$24(100 \%)$

$8(33.3 \%)$

$13(54.2 \%)$

$3(12.5 \%)$

$24(100 \%)$

\section{Hispanic, Latino, or Spanish Origin}

Yes

$2(8.3 \%)$

Ethnic Background

White

American Indian or Alaska

Native

Black or African American

\section{Sexual Orientation}

Bisexual

Straight (Heterosexual)

Queer

Questioning or unsure
$3(12.5 \%)$

$22(91.7 \%)$

$1(4.5 \%)$

$2(8.3 \%)$

$20(64.5 \%)$

$1(4.5 \%)$

$1(4.5 \%)$
Number

(\% out of 24)

\section{Household size}

3

$9(37.5 \%)$

$8(33.3 \%)$

$4(16.67 \%)$

$2(8.33 \%)$

$1(4.2 \%)$
Annual household income

$\$ 50,000-\$ 75,000$

$2(8.3 \%)$

$\$ 75,000-\$ 100,000$

$6(25 \%)$

Over $\$ 100,000$

Current Academic Position

Clinical

Visiting Professorial

Adjunct

Tenure Track/Assistant

Professor (pre-tenure)

Tenured/Associate Professor

Tenured/Full Professor

Employment Status

Full time (40+ hrs per week) $24(100 \%)$

Marital Status

Married, or in a domestic

partnership
$3(12.5 \%)$

$1(4.5 \%)$

$2(8.3 \%)$

$14(58.3 \%)$

$2(8.3 \%)$

$1(4.5 \%)$

$23(95.8 \%)$ 
Hamilton and Pinnegar (2014) define the characteristics of intimate scholarship as 1) recognizes the value of studying the particular; 2) captures nuanced meanings; 3 ) values multiple perspectives; and 4) provides opportunities for researchers and readers of research texts to imagine new responses to intractable educational problems. As motherscholars, any methodology employed to research experiences while being quarantined with children full-time must ontologically be intimate because we reject a binary division between our experiences as mothers and our experiences as scholars. Additionally, we insist that, when studying motherscholars' experiences, we need a methodology that acknowledges experiences and knowledge inclusive of non-binary identities as mothers and academics. Epistemologically, we also need methodology that recognizes knowledge beyond the traditional rational, linear model of knowing. Kuehner et al. (2016) elaborate on the epistemological foundations of reflexive inquiry:

Sympathies, prejudices, fears, emotional, mental, and physical reactions of the researcher are not conceived of as inescapable problems, but as a highly valuable epistemic resource. In this perspective, the active involvement of the researcher in the research process is not problematic, but a constitutive and valuable part of it. (p. 700)

In using a reflexive inquiry approach, the researchers were mindful of our subjectivity and intimate access to the experiences we were studying.

\section{Researchers' Positionality}

As authors and motherscholars ourselves, we recognized that our experiences informed the research design and analysis. We developed the survey questions as we reflected on our own experiences as academics and mothers during the pandemic. Broad open-ended questions were asked to encourage the sharing of personal narratives. The main survey questions, excluding those collecting demographic information, were intentionally structured as prompts for participants to use to tell stories of their experiences. These narrative responses served as the primary data for this study as further elaborated below. Members of the research team all identify as motherscholars, and this identity influenced the questions we asked and our interpretation of the data. Throughout the project, we met weekly (virtually) to discuss our experiences as motherscholars during the COVID-19 pandemic, our biases and conceptualizations of the project, and to reach consensus on our interpretation of the data.

\section{Data Collection and Analysis}

A total of 44 participants expressed interest in participating in the study, 44 were sent a link to the survey, and 24 returned the completed survey. Surveys were deemed complete if they completed all of the demographic data and provided at least one response to the open-ended questions. Surveys were all completed and submitted between May 5th, 2020 and June 6th, 2020. After identifying completed surveys, the data was uploaded into a spreadsheet and organized according to survey questions. Each member of the research team read through the data multiple times and took fieldnotes on their reactions and observations about each participant's responses. In accordance with our research question, the research team paid specific attention to identifying factors that produced and constrained the experiences participants wrote about in their open-ended narrative survey responses. These fieldnotes became the basis for our group's virtual discussions. 
As we discussed our recorded observations, we identified general themes in our observations of each participant's narrative responses. One team member took notes during these discussions.

After individually identifying themes within our observations of each participant's narrative responses, we compared and reviewed findings to converge upon agreed collective general themes. We moved on to a discussion of general themes across participants. Again, particular attention was given to the issues raised in our research question. One research team member took notes during these discussions which lasted for three virtual meetings. The research team discussed each theme in depth in an attempt to understand the experiences of each participant within each theme. The research team members then met and wrote definitions to operationalize each theme (see Table 2). The first author then went back through the narrative data to see if any themes were missed or data miscategorized according to themes. She reported to the research team that the identified themes were sufficiently defined and applied to the data. Finally, the second author categorized the eight themes into three categories based on their relevance to each other, and the team provided consensus. The three categories were: 1) Practices and Systems of Privilege; 2) Socialized Gender Roles and the Division of Labor; and 3) Ramifications of the Pandemic.

\section{Findings}

Participants reported spending an average of $30.61(S D=13.42)$ hours a week on scholarly work prior to COVID-19, and 17.74 ( $S D=13.84$ ) hours on scholarly work during COVID-19. Participants reported that, prior to COVID-19, 42.05\% (SD =38.22) of learning or online schooling was the responsibility of the participants, and that during COVID-19 they were responsible for $60.85 \%(S D=37.80)$ of learning or online schooling. On a scale of $1-10$, participants rated their typical stress level prior to the pandemic as $44.54(S D=21.97)$ and during the pandemic as 66.71 $(S D=22.85)$. For the preceding measures, note that the standard deviation remains quite similar before and after, indicating that the increased demands were somewhat uniform among participants (See Table 3).

Also, on a scale of 1-10, participants rated their loneliness on a typical day prior to the pandemic as $25.57(S D=18.09)$ and after the pandemic as $46.67(S D=30.02)$. Here, the standard deviation increased, indicating that the increases in loneliness were greater for some participants than others. We also asked participants if they struggled with mental illness. Thirteen said their mental illness had become a little worse during the pandemic, three said about the same, and two said a little better. We then present the three categories of findings containing each of the nine identified themes and subthemes (as previously summarized in Table 2). Participants' narratives were used to illustrate the categories, themes, and subthemes.

\section{Practices and Systems of Privilege}

This category that emerged from participants' responses describes their personal experiences of privilege and the interruption of certain systems due to the pandemic and being quarantined with their children while working. Specifically, the three themes of Privilege, SelfCare, and Safety and Security are included in this category. Data from themes in this category document participants' practices and systems of privilege and describe the consequences of the interruption of those practices and systems on the personal and professional lives of participants. 


\section{Table 2}

Themes Identified and Categorized from Qualitative Data

\begin{tabular}{|c|c|c|}
\hline Category & Theme & Subtheme \\
\hline \multirow[t]{12}{*}{$\begin{array}{l}\text { Practices and systems of } \\
\text { privilege }\end{array}$} & Privilege & Change in privileges \\
\hline & & Extremely privileged sample \\
\hline & & $\begin{array}{l}\text { Recognition and appreciation for } \\
\text { privilege }\end{array}$ \\
\hline & & Less privilege \\
\hline & Self-care & Sleep \\
\hline & & Social life \\
\hline & & Exercise \\
\hline & & Privacy \\
\hline & & Other \\
\hline & Safety and security & Physical safety from COVID-19 \\
\hline & & Physical safety from racism \\
\hline & & Economic safety from COVID-19 \\
\hline \multirow[t]{3}{*}{$\begin{array}{l}\text { Division of labor and } \\
\text { socialized gender roles }\end{array}$} & Shift in roles & Previous roles amplified \\
\hline & & Partner essential worker \\
\hline & & $\begin{array}{l}\text { Perception of academia and } \\
\text { flexible }\end{array}$ \\
\hline \multirow[t]{8}{*}{ Ramifications of pandemic } & Feelings about parenting & Becoming a parent and teacher \\
\hline & & Exhaustion \\
\hline & & Decreased enjoyment of parenting \\
\hline & & Growth in parenting \\
\hline & Feelings about partner & \\
\hline & Boundaries and balance & \\
\hline & $\begin{array}{l}\text { Impact of pandemic on } \\
\text { career/productivity }\end{array}$ & Impact on research productivity \\
\hline & & $\begin{array}{l}\text { Recognition that scholarly work } \\
\text { may have suffered }\end{array}$ \\
\hline
\end{tabular}


Table 3

Life Variables During the Pandemic

\begin{tabular}{lll}
\hline & Mean & S.D. \\
\hline Percentage of Household Income Comes from Participant & 59.38 & 23.77
\end{tabular}

Hours a week do you typically spend on scholarly work? (Prior to COVID-19)

Hours a week do you typically spend on scholarly work? (During COVID-19)

Percentage of learning or online schooling is responsibility of participant $39.6 \quad 40.21$

Percentage of learning or online schooling is responsibility of participant during pandemic

Percentage of household activities (cleaning, cooking, childcare) in household is typically participant's responsibility

Percentage of household activities (cleaning, cooking, childcare) in household is participant's responsibility during pandemic

How would you rate your typical stress level prior to pandemic?

How would you rate your loneliness on a typical day during the pandemic?

\section{Privilege}

Privilege can be understood as access to resources and systems (Case et al., 2012; McIntosh, 1988). Our sample of motherscholars was overwhelmingly economically privileged. Indeed, 16 out of the 24 participants reported incomes over $\$ 100,000$ USD a year, and many of the participants lived in two-income households. A majority of the participants were aware of their economic privilege and acknowledged it in their responses. It is also worth noting that a majority of the motherscholars who completed the questionnaire identified as white, and only three participants 
identified as women of color, indicating that a large portion of the sample was privileged in multiple areas.

Despite economic privilege, as women scholars navigating academia, participants also reflected on ways that they were less privileged within their professional environments. Factors such as rank status and gender representation in departments were mentioned. We see in later categories that systems of privilege were disrupted, but here responses reflect participants' views that they recognized many privileges that remained intact. The following subthemes of privilege emerged from the participants' responses and further elaborate their experiences.

Change in Privileges. Many of the motherscholars reflected on ways that their access to support and resources changed due to the pandemic and following shelter-in-place orders. These changes impacted their well-being and ability to complete professional responsibilities. For instance, one participant stated, "I no longer have as many resources as I once did." Another motherscholar expanded on this experience by expressing:

\section{All my supports I had set up-in person new mom support groups, in-person new mom workout classes that the babies would sleep because you're moving the strollers, family and friends scheduled to come by and help/bring food and watch the baby so I can work or take care of me, all of that evaporated.}

For others, the privilege they held did not change, but became more apparent, "Privilege has not changed, but is easier to see. My family did not lose income, access to any necessities. This is normal for us, but highlights how privileged we are."

Privileged Sample. The participants' acknowledgement of their privilege highlighted that, although academia does present challenges to its female faculty, it also offers significant privileges. For example, a motherscholar reflected on her medical and social privilege by stating, "I have every privilege and benefit--medical, social." Several participants also acknowledged that academia offers economic security, some job stability, and the ability to work safely from home, as well as access to parental leave or other forms of support:

Because I have tenure, my job has been very stable. We still have access to most everything we need. As a well-educated individual with friends in public health and epidemiology fields, I feel like I have been able to stay informed about what we need to do to keep ourselves healthy. I have food, clothes, shelter, health insurance. I worry about those in different circumstances than mine.

Finally, one motherscholar also discussed the way her race provided her extra privilege as she and her family do not have to worry about their well-being and safety in the same way as BIPOC do: "I feel privileged every day. We do not have immediate concerns about money or health. We are white and do not have daily concerns or fears about our well-being because of our race or ethnicity."

Loss of Privilege. A motherscholar stated that, as faculty, she has less power than university administrators regarding decisions made by her academic institution in response to the pandemic: "With lack of voice in decisions related to returning to campus in the Fall." Another motherscholar reflected on how her concerns regarding tenure and rank advancement were also linked to economic uncertainty as universities across the nation furloughed faculty, cancelled raises, or engaged in hiring freezes. For some motherscholars, these concerns caused them to want 
to overperform to secure funding immediately and ensure future economic stability.

\section{Self-care}

According to the World Health Organization (WHO; 2020), self-care is what people do for themselves to establish and maintain health, and to prevent and deal with illness. It is a broad concept encompassing "hygiene (general and personal), nutrition (type and quality of food eaten), lifestyle (sporting activities, leisure etc.), environmental factors (living conditions, social habits, etc.) socio-economic factors (income level, cultural beliefs, etc.), and self-medication" (WHO, 2020, para. 3). In the responses of the participants in this study, these motherscholars described how they had used their socioeconomic privilege to access previously constructed systems through which to attend to their self-care needs. The systems these motherscholars had in place allowed them to participate in self-care practices which, in turn, they believed helped them be productive and successful at work. However, the COVID-19 pandemic interrupted those systems.

As many mothers will attest, finding time for self-care can be a challenge in the best of times. As a result of pandemic conditions, many participants found their ability to use their socioeconomic privilege to enact systems of self-care logistically limited and compounded by increased responsibilities for childcare and home schooling. One motherscholar remarked that one of the hardest parts of the pandemic was: "No down time for myself (eg., gym, exercise, social visits or calls) unless everybody is asleep, at which point I am exhausted." Participants in the study frequently reported that they were missing their practice of self-care, which became extremely limited with the onset of the COVID-19 pandemic. Within this category, common subthemes were identified including sleep, social life, exercise, privacy, and other.

Sleep. The most common theme in this category was of participants not getting the sleep they felt that they needed in order to function well. Many reported working all day helping their children with schoolwork, only to feel like they needed to spend the evening and nighttime hours working on their scholarly work. For example, one motherscholar wrote: "[There was] a week where I was up until 3:00 a.m. multiple days in a week trying to get work done that I could not get done during 'regular' work hours." There is a strong relationship between stress and sleep, in which stress tends to disrupt healthy sleep patterns, and unhealthy sleep patterns tend to cause added stress (Medic et al., 2017). This was illustrated by other motherscholars who reported trying to sleep but being awakened by nightmares: "I'm unable to get a good night's sleep because I wake up in a panicked state or have nightmares."

Social Life. Many of the motherscholars in our sample lamented that they were lonely and were not able to have the social interaction that they needed in order to feel balanced. Again, they attributed this, not only to limited time, but also to the need to social distance and/or quarantine. One motherscholar aptly stated: "Women especially need each other and support." Another participant wrote about how she desperately wanted to engage in social interaction, but she was too tired at the end of the day: "I am required to go in to work as an essential employee and deal with my family who has been trapped in the house all day. It is exhausting - too tired to engage in personal life but desperately miss it."

Exercise. Some participants in our sample described feeling like their regular self-care routine was disrupted because they did not have the same opportunities to exercise as they did prepandemic: "[I] went from trying my best to non-existent. I had a schedule of gym time, etc., and now it's all up in the air."

Privacy. Privacy is also a social issue that can affect safety and freedom of socially marginalized individuals. Success at both work and in the home has been a pressure felt by women for decades. Invasion of privacy could potentiate unequal gender bias against women scholars 
(King, 2008). During the pandemic, many motherscholars had to work from home with online meetings that streamed live activities occurring in their previously private spaces. Bedrooms, bathrooms, kitchens, and living rooms were once a place of refuge with no need to keep up appearances. During the pandemic, these private spaces became accessible through, not only the individuals' cameras, but through the online cameras and zoom meetings of other individuals in the household. Teachers, therapists, and even activity groups began requesting zoom meetings with parents and children. A place where rules for attire had not existed became publicly displayed areas. Someone walking through the kitchen in a bathrobe could be caught on camera. Disputes between family members or even intimate moments could be viewed or heard by others outside the home.

Another aspect of privacy that participants noticed was the lack of privacy that they typically enjoyed surrounding their work. Many motherscholars reported enjoying the privacy they experience when they are at work, and that experience was disrupted during the pandemic when participants were working at home. Children were walking in on work meetings and colleagues could see homes over the camera: "My daughter walks in on meetings or lectures. My colleagues have seen rooms in my house that are private." Even within the constructs and walls of the family, privacy decreased during the pandemic for motherscholars. Instead of family members leaving for school, activities, or work, they had to adjust and attempt to do activities within the confines of their home with family members present. In referring to the difficulty of always being around family, one motherscholar wrote: "My only downtime is going to the bathroom and showering, and even then, I have a 50\% chance of being interrupted." The constant presence of people in the home increased noise and tension for participants. One reported being unused to the silence that she would encounter in places other than her home: "I find myself in a quiet space after a shower and realize I haven't "heard" silence in days."

Other. This sub-category included participants whose experiences with self-care had different manifestations. One participant wrote about how she experiences PTSD from a childhood experience and that she no longer has the time to engage in the coping mechanisms that she previously found helpful:

I live with PTSD resulting from my own childhood abuse and neglect. I have found it more difficult to manage the symptoms of PTSD during the shutdown. For me, the symptoms are stronger and more frequent because I am not able to rely on my usual coping mechanisms. . .

Interestingly, three participants wrote about how, in some ways, their self-care had actually improved with the pandemic. One wrote:

In some ways I have more of what I want now. I sleep later, take almostdaily walks by myself, often lie down mid-day while my toddler naps, spend more time outdoors and with my children, even started an at-home date night with my partner when our children go to bed early enough.

\section{Safety and Security}

The intersection between identities of privilege and marginalization and safety was a theme that emerged from the data. Participants mentioned concerns about the physical safety of themselves and their families, both from COVID-19 and also from the effects of racism.

Physical Safety from COVID-19. With the quick spread of the COVID-19 pandemic, motherscholars worried about their health and the health of their families: 
I was in another state at an academic conference when the pandemic was declared. I had to be there. It was extremely stressful and I came home early. I didn't know what to do, if I should quarantine at a hotel or come back home. Thankfully everyone was okay but I have never been so stressed out.

In addition to the general worry about the safety of their family from COVID-19, participants that were new mothers reported especially worrying about the safety of their newborn child: "I felt most overwhelmed with a baby, not knowing the impact the virus could have on my child."

Physical Safety from Racism. Women who identified as People of Color (POC) specifically mentioned concerns around safety related to their race as part of their narrative:

I am a minority and I am female so before the shutdown, I was already trying to hide. People had been incredibly bold displaying their hate. After the shutdown it has worsened. Being in healthcare doesn't help; I try to make sure people don't see me in my scrubs, I have no idea who is going to yell at me for helping at the hospital. I watch where I am, I watch who is around me at all times. It's exhausting.

Another participant remarked that she feels unsafe all of the time: "My view of being Black during COVID-19 has definitely shifted since the shutdown. I feel ominously unsafe all of the time."

Economic Insecurity. The concerns reported regarding tenure and rank advancement were also linked to economic uncertainty as universities across the nation furloughed faculty, stopped raises, or engaged in hiring freezes. For some motherscholars, these concerns caused them to want to overperform in order to secure funding: "As well as the uncertainty of the situation, I am in a relatively stable soft money position but I feel the need to overperform now, e.g., to try for additional grants in case some funding goes away."

\section{Socialized Gender Roles and the Division of Labor}

Participants' narrative responses yielded three themes in the category of socialized gender roles and the division of labor within the home: Shift in Roles (including previous roles amplified), Perceived Flexibility of Academia, and Other. Data from themes in this category portray participants' lived experiences of gender roles within their homes and how those gender roles were impacted by pandemic conditions necessitating quarantine with their children while working. With the elimination of childcare and resulting addition of children at home, most participants felt overwhelmed by the increased amount of labor involved in parenting during a pandemic. Many motherscholars lost household help in the form of nannies or house cleaners, thus leaving more labor for the motherscholar to take on. Twenty-three of the 24 women in our sample were partnered, and half (12) wrote something about the division of labor in the household. 
Shift in Roles.

Many of the women in our sample wrote about a shift in roles from pre- to post-COVID19 shutdown. These tended to be around the themes of differences in flexibility of work, spouses being considered essential workers, and previous roles being amplified. Many of the participants in our sample wrote about how they had worked hard to establish an egalitarian marriage, but that there was a significant shift in household responsibilities once COVID-19 hit:

My husband and I have always had a pretty egalitarian marriage. It's not always 50/50, but we try to reach that level. My husband, during this time, has taken on more of a supervisor rule during the times I have to work, but I'm the one that sets up all the centers to keep my son occupied. My husband hasn't done anything when it comes to the teaching aspect. During this time, Ifeel like our parenting roles have become unequal with me doing more of the work.

Another motherscholar similarly wrote:

I would characterize the balance of parenting roles between my spouse and I as generally equal before COVID-19. But with the shift to working from home, that has been a huge shift... My own work is squeezed in during nap time and after bedtime. I am essentially squeezing what should traditionally be a 30-40 hour workweek into the 10 hours I can cobble together in snatches of moments.

Previous Roles Amplified. For a few of our participants, the roles in the household didn't necessarily change, but previous roles were amplified. For example, one participant commented that the tasks she was typically responsible for were the ones that intensified during the pandemic:

I think my partner and I are still sharing many of the same parenting roles we did before. I was usually the person to help with homework, and with the kids' emotional needs. Those tasks have just increased since we have all been at home.

Partner Essential Worker. Some participants in the study identified their partners as "essential workers," and thus their partners were not able to work at home and contribute to childcare and household tasks. They remarked that this further contributed to the inequity of household tasks and parenting during the pandemic:

I definitely took on the role of being more so the parent caring for the child during COVID-19. This is usually very much shared between both parents, but as my husband was an essential government worker and had set hours - it was important for him to be available - so there were days where I did not get any work done, and instead was primarily responsible for my son.

Perceived Flexibility of Academia. For many, the shift in responsibility over household and childcare tasks was attributed to the difference in perceived flexibility between the work roles of each of the partners. The participants in this study were involved in academic roles, which in 
many places have a reputation for being flexible in terms of the hours spent at work versus at home. Many participants wrote that because their jobs were seen as more "flexible" than those of their partners, they became responsible for more of the household and childcare tasks. One woman described the balance of parenting roles between her and her spouse as generally equal, but that shifted when people were starting to work from home:

\section{My husband's job is much more 9-5, with back-to-back meetings and limited flexibility. Being at home has amplified the actual/presumed "flexibility" of an academic job, so now I need to help my kiddo with school work, and anything I do is done on the weekend or evenings.}

As one participant wrote, the interpretation of her academic job as more "flexible" meant a significant shift in the way that housework was divided:

Prior to covid, my husband and I split all the housework 50/50 and were able to really navigate parenting responsibilities fairly. However, because my job is the more flexible one, I have now taken on about $95 \%$ of parenting responsibilities and about $70 \%$ of household responsibilities.

\section{Ramifications of the Pandemic}

The four themes assigned to this category document the pernicious and potentially chronic repercussions of the pandemic on motherscholars. With their practices and systems of privileges interrupted, data portrays how they were more fully exposed to the negative impacts of socialized gender roles and other forms of oppression. The themes that emerged around the ramifications of the pandemic were feelings about parenting (including being both a parent and teacher, exhaustion, decreased enjoyment of parenting, and mixed feelings about parenting), feelings about partner, boundaries and balance, and ramifications on scholarly work and productivity.

\section{Feelings About Parenting}

Parenting presents many challenges for working women under normal circumstances. Access to affordable childcare and the stress of juggling multiple roles are experiences felt by working mothers. Data from a report published by the Stanford Institute for Gender Research shows that $86 \%$ of male academics have stay-at-home partners (Schiebinger et al., 2008). Overall, male scholars are far more likely to have a stay-at-home partner than female scholars (Schiebinger et al., 2008). The motherscholars who participated all reflected on their own experience of mothering during the pandemic and under isolation orders. One participant succinctly reported: "I feel resentment about being a mother. I don't think I am "enjoying" motherhood in the same way I might have. I hate it." Four themes emerged from their reflections: becoming a parent and a teacher, exhaustion, decreased enjoyment of parenting, and growth in parenting.

Becoming a Parent and Teacher. As the COVID-19 pandemic reached the U.S. and quickly worsened, leading to the need for individuals and families to isolate, schools, daycares, and other childcare services were forced to close. These systems that mitigated gender roles particularly for motherscholars disappeared. The motherscholars in our sample reported they felt unprepared for this sudden shift in their role: "Since I've become my son's teacher, I've had to take on a role I don't feel prepared for." Furthermore, the sudden need to be both a parent and a teacher caused 
many motherscholars to feel frustration and resentment. Some reflected on difficulties finding enjoyment in mothering. For instance, one participant wrote:

Prior to COVID, I really enjoyed all the quality time I spent with my little one. Now I am easily annoyed and give her the reign to watch as much youtube as she wants. With my older children, the relationship has become very strained because they are not taking schooling as serious, and it becomes a daily argument.

Overall, participants in the sample reported difficulty enjoying motherhood as the roles of teacher and parent became combined: "[It is] much harder to be a parent AND teacher. I prefer only one at a time."

Exhaustion. The general sentiment expressed by many motherscholars was exhaustion with the multiple roles they were taking on. Many participants reported feeling physically and emotionally exhausted, which often left them with no energy to fulfill their parenting roles. We can observe that the sudden change in the demands of parenting and the loss of balance and boundaries significantly impacted exhaustion: "It's frustrating. Parenting has become more difficult. Sometimes I have the stamina to argue and make my teenagers follow through with school work."

Taking the Fun Out of Parenting. Another aspect of the experience of parenting that appeared to change for the motherscholars was their ability to have fun being a parent. This can be connected to other themes that emerged from the data, including loss of balance and boundaries, lack of time and energy for self-care, and professional stress:

Our son is preparing for Head Start in the fall, so although he is not expected to do formal "online learning," we still feel pressure to make sure he continues to learn and is ready for the next step in his education. This has taken some of the fun out of parenting.

Growth in Parenting. In contrast to other participants, one motherscholar wrote that she has become more patient as a result of taking on different roles at home: "In schooling my son, I've seen sides to his personality that I don't normally get to see. This has resulted in me being more patient and more encouraging than I typically need to be with him." For many, the change in roles was not that simple, and they experienced both pros and cons: "In some ways, I'm definitely a better mother than I thought I was. In other ways, I have less tolerance for being a mother." Differences in reported parenting experiences may have been caused by the age of the children in the home. One motherscholar pointed out nuances in her experience based on her own children's ages: "My teen son and I are closer and we talk about everything, but my 3-year-old is a little hard to handle being home all the time."

\section{Feelings About Partner}

Not all participants in the study indicated they had a partner. Moreover, participants were not directly asked about their feelings toward their partner during the pandemic. Even so, some expressed frustration with their partners as they tried to co-parent. Motherscholars expressed that they perceived their partners as having a lack of understanding or empathy for the balance between parenting and work for a motherscholar. While a partner may have increased the number of hours helping with domestic chores or childcare, the motherscholars perceived that the increased care 
was not equal in burden. One participant expressed her frustration at having to explain to her husband why his help was needed:

Trying to multitask getting it all done simultaneously was frustrating. When my spouse came home from work, he acted as though it was a massive inconvenience for him to help our child - not recognizing that I had been doing it all day and needed time to finish my work. It was almost more effort to explain to him why he should help, as opposed to just doing it myself.

The burden of childcare weighed on both partners, but the motherscholars tended to take on a larger proportion of the care. Motherscholars tended to mention sentiments about their partners being unwilling or unable to handle the increased burden in a similar way to the participant. One participant gave an example of a time when she was trying to work while her husband was caring for the baby, but his emotional stress and frustration made it more difficult:

I was on a work zoom and my baby was going ballistic which sent my husband over the edge (normally it's fine but he seems very overwhelmed by not having a break from the kids), and I had to go get the baby. His stress and frustration is my biggest source of overwhelm.

The increased frustration, stress, and lack of felt empathy manifested with negative reactions. An example included shouting at a partner:

I shouted at my husband for allowing my kiddo to interrupt my meeting. His response was "I told him not to come in" and my response was, "he is a child, and you have to make sure he's not interrupting me. I have ONE meeting today for ONE hour. How many times has he interrupted YOUR meetings--any of them?" (The answer is NONE)."

Clearly, participant responses included a mixture of concern for their partners and positive adaptation, while simultaneously expressing frustrations via negative coping during this period. It is likely that such complexity of emotions for one's partner were common in relationships before being quarantined with partner and children.

\section{Boundaries and Balance}

Working to achieve balance is a constant struggle in the life of many working mothers (Gatrell \& Cooper, 2008), and for many, the loss of support systems from the closure of schools and daycares associated with the pandemic added an additional burden to the pursuit of balance

between work and home. Many motherscholars discovered that they were "not as good at balancing as [they] thought" and that "there is no work life balance." Specifically, one participant wrote:

I felt like I was pretty good at boundaries before-giving myself space for me, and giving my family access to me. The natural boundaries that my kids' school and extracurricular activities created really helped me with that. It's been harder for me to maintain boundaries when we are all living together $24 / 7$. 
For some, the flexibility of working from home added to the difficulty of achieving balance: "While I like the flexibility, I feel overwhelmed and have difficulty placing priorities with family and work obligations, something that I did not have trouble with before." When asked about balance, another motherscholar wrote: "There is no balance. I am barely trying to squeeze in the little professional life I can for my own sanity. My personal life is also gone. I am just in baby, caretaking, and house-manager mode. It's awful." Most motherscholars attributed the lack of balance to the experience of trying to simultaneously work and homeschool their children. For example: "I feel like there is no longer any balance. I'm working and schooling during the day. In the evenings, I'm prepping both for my university teaching and for what I have to teach my son the following day."

An added challenge to achieving balance for most participants was the elimination of the boundaries between work and home. One participant remarked: "Now, work and family time is very blended. There are no set boundaries for work time as my husband and I are both juggling caring for our son while working full time." Participants reported that not only are the boundaries between work and home blurred, but one parent wrote about how the boundaries between being her child's mother and teacher were also being blurred: "They [home and work] are bleeding together." Of particular importance was the emotional toll that the blending of home and work exacted on many of the participants. One motherscholar wrote:

\section{I feel most overwhelmed when I get work to do that needs a quick turnaround, or get asked to do new work that is optional and need to set a clear boundary if I want to say no. Those are the times when the parenting and awful news and increased logistics of groceries while sheltering in place and grief and anger all come together.}

The impact of the added emotional toll of blending home and work affected participants differently. In the case of at least one participant, the stress caused her to overperform: "There is less balance, more stress, and this results in me trying to overcompensate and overperform." For another participant, the blurring of boundaries meant that she shifted toward more focus on her personal life:

\section{I think that it has become less balanced and definitely shifted to more so focus on personal life rather than professional life - more so as a necessity based on conditions in my house and that I don't have any imminent deadlines for my faculty position.}

At least one participant felt like the balance had gone well for her and her family. She remarked: "However, the balance between work time and time with my daughter has gone well." Although, it may be worth noting that this particular participant also reported having a partner who significantly "stepped up" and provided more childcare than he/she did before the pandemic.

\section{Impact on Career/Productivity}

The COVID-19 pandemic has brought significant challenges for academics and scholars across the country. The two sub-categories regarding the pandemic's impact on career and productivity highlight some of those challenges: impact on research productivity and the recognition that the quality of scholarly work produced during the pandemic suffered. The experiences reported by the motherscholars are consistent with emerging data regarding the impact 
of the pandemic on female scholars in general. Multiple research journals have reported a decrease in journal submissions by female scholars in March and April 2020 (Oleschuk, 2020). Furthermore, multiple researchers and journals have shown trends indicating that male academics' productivity (as indicated by rates of submissions and first-author or sole-authorship papers) has increased during the pandemic compared to women's (Dolan \& Lawless, 2020; Fazackerley, 2020; Flaherty, 2020; Fuchs-Schündeln, 2020). These trends appear to especially impact early career female academics and are consistent with the experiences reported by our participants (Vincent-Lamarre et al., 2020).

Impact on Research Productivity. Motherscholars were concerned about the impact of the pandemic and changes in their productivity on their career. Several motherscholars discussed difficulties fitting their scholarly work in their daily schedules which impacted their ability to work on research tasks such as writing and revising papers.

Scholarly work just doesn't fit. . .I have found that I consider academics who quarantined alone "lucky" since they could use time differently. I see others writing, researching, revising and I just can't with my responsibilities at home. It seems like working in an office is a privilege for moms.

For some motherscholars, this caused worry regarding the future of their career, their ranking status, and even their ability to stay in academia:

I am starting to rethink staying in higher education. I am afraid of the expectations that we will have as we come back. Administration can see that we can make it work from online, that we can do this with kids at home, and chaos in the background. This is not good.

Recognition that Scholarly Work Quality May Have Suffered. The changes in productivity also involved concerns regarding the quality of work. Recognizing that they could not juggle all of their responsibilities perfectly, some motherscholars reflected on the impact of the pandemic on the quality of their scholarly work. As one participant put it:

Mostly it has intensified the feelings and perceptions I already had. Wanting for myself what I want for all parents and vice versa. Knowing academia moves slowly and that I prioritize my family over working nights and weekends so my 'progress' as a scholar will be slower and more rough around the edges than other people.

Interestingly, this participant situated their experiences in the larger context of academia and conscious choices they previously made regarding how they chose to navigate it. This historic perspective on their work in academia and their mothering highlights the tensions that motherscholars have chronically faced. Additionally, it is clear that, in this participant's experiences, the COVID-19 pandemic has intensified old tensions.

\section{Limitations and Directions for Future Research}

Limitations of this study include the small number of participants (24). However, the small sample size used in this study did facilitate gathering and analyzing narrative data. Sampling with 
the intent to include marginalized groups that may be typically under or unrepresented was useful, but is non-probabilistic and may not be generalizable as a whole. Future research into the ways in which crisis situations (such as the COVID-19 pandemic) impact systems that serve to mitigate socialized gender roles would benefit from a larger sample size. The qualitative narrative method provides insight into the lives of the motherscholars, but is limited and prone to recall bias of participants. Future research could explore effects of the pandemic on motherscholars with quantitative measures of the ways in which these conditions disproportionately impact professional women. While there were inequities between motherscholars and their partners or male colleagues, this study focused only on the perceptions of the motherscholars. Additional studies might seek to include both parents' perceptions.

\section{Conclusions}

The location of this study was firmly grounded in motherscholars' homes. During quarantine due to the COVID-19 pandemic, the residences of these motherscholars simultaneously served as workplaces, schools, and homes. Through our analysis of the narrative data, we systematically attended to the professional, public, and intimate dimensions of the participants' experiences in their homes while quarantined with their children. This attention to location adheres to feminist scholar Collins' (1990) insistence that we acknowledge the ways in which theory is positioned by those who are theorizing and where they are doing it. Additionally, our findings were consistent with emerging literature regarding the experiences of mother academics during a pandemic and the need to create solutions that fully address the challenges they face (Kasymova et al., 2021).

Our findings demonstrate the tenuous hold these participants had on gender equity and on balancing working and mothering, and just how quickly such 'equity' and 'balance' fall apart when the systems women have built for themselves to mitigate socialized gender norms are interrupted. Research and policy attention must be given to the ways in which the institutions of motherhood, academia, and other professions can formalize more robust systems that allow women to pursue professional goals as men do. This study contributes to a theoretical understanding, grounded in data, of the ways in which socialized gender roles and systems designed to mitigate them are impacted by crisis conditions. In this manner, this study has the potential to guide future research and policy efforts.

During pre-pandemic conditions, the well-educated, middle-class motherscholars in this study had created systems whereby they outsourced many of the traditionally gender-specific household responsibilities that they did not have time for or did not feel particularly competent at doing. These systems served to mitigate the socialized gender roles within the homes of the participants. However, the COVID-19 pandemic interrupted these mitigating systems. With such systems interrupted, and in the stress and trauma of quarantine conditions, participants, their partners, and children seemed to have reverted back to traditional gender roles even in partnerships grounded in equality. These findings document how group privilege operates at the individual level (Case, 2013; Case et al., 2012) by showing how participants utilized their social privilege to organize systems to lessen the inequitable responsibilities of the institution of motherhood.

Our findings urge additional research into how privilege operates through systems organized by women. It must be acknowledged that it was only because of their social privilege that the participants in this study were able to access and organize supportive systems. This reality begs future research into the experiences of women who do not work in professions that yield middle- to upper-middle-class socioeconomic status and are marginalized through other components of their intersectional identity. We also document the ways in which crisis conditions 
compromise professional women's privacy and intersecting identities within their homes and in professional settings. The physical locations of home and office have been collapsed, temporarily or permanently, due to the COVID-19 pandemic. Lapayese (2012) notes the work of feminist scholar Ruddick's (1982) notion of humility as a willingness to acknowledge all that is beyond one's control, and yet to not become powerless. Certainly, the narrative data from participants in this study document many things beyond participants' control, and nevertheless these motherscholars persisted.

\section{References}

Arum, R. \& Stevens, M. L. (2020, March 18). What is a college education in the time of coronavirus? The New York Times. https://www.nytimes.com/2020/03/18/opinion/collegeeducation-coronavirus.html

Bagilhole, B., \& Goode, J. (2001). The contradiction of the myth of individual merit, and the reality of a patriarchal support system in academic careers: A feminist investigation. European Journal of Women's Studies, 8(2), 161-180. https://doi.org/10.1177/135050680100800203

Bryan, C. (2019). Social reproduction and the labours of motherhood. In L. O'Brien Hallstein, A. O'Reilly, and M. Vandenbeld Giles (Eds.), The Routledge Companion to Motherhood (pp. 331-342). Taylor \& Francis Group. https://ebookcentral.proquest.com/lib/byu/detail.action?docID=5975284

Cardozo, K. M. (2017). Academic labor: Who cares? Critical Sociology, 43(3), 405-428. https://doi.org/10.1177/0896920516641733

Case, K.A. (2013). Deconstructing privilege: Teaching and learning as allies in the classroom. Routledge.

Case, K. A., Iuzzini, J., \& Hopkins, M. (2012). Systems of privilege: Intersections, awareness, and applications. Journal of Social Issues, 68(1), 1-10. https://doiorg.erl.lib.byu.edu/10.1111/j.1540-4560.2011.01732.x

Clandinin, D. J., \& Connelly, M. F. (2020). Narrative inquiry: Experience and story in qualitative research. Jossey-Bass.

Clandinin, D. J., \& Murphy, M. S. (2009). Comments on Coulter and Smith: Relational ontological commitments in narrative research. Educational researcher, 38(8), 598-602.

Coin, F. (2018). When love becomes self-abuse: Gendered perspectives on unpaid labor in academia. In Y. Taylor (Ed.), Feeling academic in the neoliberal university: Feminist flights, fights and failures (pp. 301-320). Palgrave Macmillan. https://www.academia.edu/36197588/When_love_becomes_self_abuse_gendered_perspe ctives_on_unpaid_labor_in_academia

Collins, P. H. (1990). Black feminist thought: Knowledge, consciousness, and the politics of empowerment.

Unwin

Hyman.

https://openlibrary.org/books/OL1872358M/Black_feminist_thought

Cooper, M., \& Pugh, A. J. (2020). Families across the income spectrum: A decade in review. Journal of Marriage and Family, 82(1), 272-299. https://doi.org/10.1111/jomf.12623

Cutri, R. M., \& Mena, J. (2020). A critical reconceptualization of faculty readiness for online teaching. Distance Education, 41(3), 361-380.

Cutri, R. M., Mena, J., \& Whiting, E. F. (2020). Faculty readiness for online crisis teaching: Transitioning to online teaching during the COVID-19 pandemic. European Journal of Teacher Education, 43(4), 523-541.

Dolan, K., \& Lawless, J. L. (2020). It takes a submission: Gendered patterns in the pages of AJPS. American Journal of Political Science, 22(1), 121-134. 
Falci, C. D., \& Watanabe, M. (2020). Network marginalization of women in the workplace: A case in academia. Journal of Women and Minorities in Science and Engineering, 26(2), 155175. https://doi.org/10.1615/jwomenminorscieneng.2020029186

Fazackerley, A. (2020). Sacked or silenced: Academics say they are blocked from exploring trans issues. The Guardian. https://www. theguardian. com/education/2020/jan/14/sackedsilenced-academics-say-they-are-blocked-from-exploring-trans-issues.

Flaherty, C. (2020, August 20). Women's journal submission rates continue to fall. Inside Higher Ed. https:/www.insidehighered.com/print/news/2020/08/20/womens-journal-submissionrates-continue-fall

Fuchs-Schündeln, N. Gender structure of paper submissions at the Review of Economic Studies during COVID-19: First evidence. mimeo, 2020.

Gatrell, C. J., \& Cooper, C. L. (2008). Work-life balance: Working for whom? European Journal of International Management, 2(1), 71-86. https://doi.org/10.1504/EJIM.2008.016929

Gonzales, L. D. (2018). Subverting and minding boundaries: The intellectual work of women. The Journal of Higher Education, 89(5), 677-701. https://doiorg.erl.lib.byu.edu/10.1080/00221546.2018.1434278

Gülbahar, Y., \& Adnan, M. (2020). Faculty professional development in creating significant teaching and learning experiences online. In L. Kyei-Blankson, E. Ntuli, \& J. Blankson (Eds.), Handbook of research on creating meaningful experiences in online courses (pp. 37-58). IGI Global. https://doi.org/10.4018/978-1-7998-0115-3.ch004

Garbe, A., Ogurlu, U., Logan, N., \& Cook, P. (2020). COVID-19 and Remote Learning: Experiences of Parents with Children during the Pandemic. American Journal of Qualitative Research, 4(3), 45-65. https://doi.org/10.29333/ajqr/8471

Hamilton, M. L., \& Pinnegar, S. (2014). Intimate scholarship in research: An example from selfstudy of teaching and teacher education practices methodology. LEARNing Landscapes, 8(1), 153-171. https://doi.org/10.36510/learnland.v8i1.680

Hechinger, J. \& Lorin, J. (2020, March 19). Coronavirus forces $\$ 600$ billion higher education industry online. Bloomberg Businessweek. https://www.bloomberg.com/news/articles/2020-03-19/colleges-are-going-onlinebecause-of-the-coronavirus

Kasymova S., Place J., Billings D., et al. (2021) Impacts of the COVID-19 pandemic on the productivity of academics who mother. Gender, work, and organization 28(S2), 419-433.

King, E. B. (2008). The effect of bias on the advancement of working mothers: Disentangling legitimate concerns from inaccurate stereotypes as predictors of advancement in academe. Human Relations, 61(12), 1677-1711. https://doi.org/10.1177/0018726708098082

Kuehner, A., Ploder, A., \& Langer, P. C. (2016). Introduction to the special issue: European contributions to strong reflexivity. Qualitative Inquiry, 22(9), 699-704.

Lapayese, Y. V. (2012). Mother-scholar:(Re) imagining K-12 education (Vol. 85). Springer Science \& Business Media.

Marmot, M. (2004). Status syndrome. Significance, 1(4), 150-154.

Matias, C. E. (2011). Paying it forward: Mother scholars navigating the academic terrain [Paper presentation]. American Educational Research Association (AERA), AERA Division G Highlighted Panel.

Matias, C. E., \& Nishi, N. W. (2018). ParentCrit epilog. International Journal of Qualitative Studies in Education, 31(1), 82-85.

McIntosh, P. (1989). White privilege: Unpacking the invisible knapsack [Electronic version]. Independent School, 49(2), 31-35. 
McMurtrie, B. (2020, March 20). The coronavirus has pushed courses online. Professors are trying hard to keep up. The Chronicle of Higher Education. https://www-chroniclecom.erl.lib.byu.edu/article/The-Coronavirus-Has-Pushed/248299

Medic, G., Wille, M., \& Hemels, M. (2017). Short- and long-term health consequences of sleep disruption. Nature and Science of Sleep, 9, 151-161. https://doi.org/10.2147/nss.s134864

Minello, A. (2020). The pandemic and the female academic. Nature Worldview, https://doi.org/10.1038/d41586-020-01135-9.

Myers, K.R., Tham, W.Y., Yin, Y. et al. (2020). Unequal effects of the COVID-19 pandemic on scientists. Nature Human Behavior 4, 880-883. https://doi.org/10.1038/s41562-020-0921$\mathrm{y}$

Oleschuk, M. (2020). Gender equity considerations for tenure and promotion during COVID-19. Canadian Review of Sociology, 57(3), 502-515. https://doiorg.erl.lib.byu.edu/10.1111/cars.12295

Pinnegar, S. E., \& Hamilton, M. L. (Eds.). (2015). Knowing, becoming, doing as teacher educators: Identity, intimate scholarship, inquiry. Emerald Group Publishing.

Reissman, C.K. (2008). Narrative methods for the human sciences. Sage Publications, Inc.

Rich, A. (1995). Of woman born: Motherhood as experience and institution. WW Norton \& Company.

Ruddick, S. (1982). Maternal thinking. In A. C. Cafagna, R. T. Peterson, C. A. Staudenbaur (Eds.), Philosophy, Children, and the Family (pp. 101-126). Springer. https://doi.org/10.1007/9781-4613-3473-6_11

Schiebinger, L. (2006). Women of Natural knowledge. In The Cambridge history of science. Vol. 3: Early modern science(pp. 192-205). Cambridge Univ. Press.

Van den Brink, M., \& Benschop, Y. (2012). Gender practices in the construction of academic excellence: Sheep with five legs. Organization, 19(4), 507-524. https://doi.org/10.1177/1350508411414293

Viswanath, S., \& Mullins, L. B. (2020). Gender responsive budgeting and the COVID-19 pandemic response: A feminist standpoint. Administrative Theory \& Praxis, 43(2), 230-244. https://doi.org/10.1080/10841806.2020.1814080

World Health Organization. (2020). What do we mean by self-care? https://www.who.int/reproductivehealth/self-care-interventions/definitions/en/

Zhai, Y., \& Du, X. (2020). Addressing collegiate mental health amid COVID-19 pandemic. Psychiatry Res, 288, 113-333. https://doi.org/10.1016/j.psychres.2020.113003

\section{Notes on Contributors}

Christine Rae Platt is board-certified family nurse practitioner and a dual degree (DNP/PhD) doctoral candidate from the University of Arizona College of Nursing. She continues to provide family-centered care in the clinic and community while specializing in dermatology since 2014. Her research focus is on at-risk and often marginalized populations. She has a particular interest on decreasing health disparities and improving long-term outcomes for children in foster care. Previous research includes families raising children with disabilities. E-Mail: crplatt@email.arizona.edu

Melissa Goates-Jones, $\mathrm{PhD}$ is Assistant Professor in the Psychology Department in the College of Family, Home, and Social Sciences at Brigham Young University. Her research focuses on psychotherapy process and outcome, as well as the experience of women and people from traditionally marginalized communities in academia. Recent publications focus on addressing 
microaggressions in group therapy and the impact of Covid on mental health services in a university counseling center. E-Mail: melissa_jones@byu.edu

Ramona Maile Cutri, $\mathrm{PhD}$ is an associate professor at Brigham Young University's Teacher Education Department. Cutri's research attends to the complexities of technology integration in higher education. Her work contributes a criticality to research on eLearning and highlights the tensions between the culture of academia and the potential and demands of online teaching. Cutri explores how technology can facilitate the pedagogical and dispositional goals of critical multicultural teacher education. She has produced important work that documents the emotional work involved in multicultural education teacher education and managing affective polarization to facilitate students' thinking, dispositions, and development as teachers. E-Mail: ramona_cutri@byu.edu

Louise Fidalgo Wheeler, $\mathrm{PhD}$ is an assistant clinical professor in the Counseling and Psychological Services at Brigham Young University. She also has a joint faculty appointment with the department of Counseling Psychology and Special Education where she teaches a practicum class and a multicultural counseling class. Her research focuses on the impact of discrimination and marginalization on health. E-Mail: louise_wheeler@byu.edu.

Tamara Walden, $\mathrm{PhD}$ is a clinical licensed psychologist at the University of Central Florida. Her values, training, and experience allow her to help clients by bridging the gap between diverse experiences not well-understood with the latest professional insights and approaches in psychology. She specializes in women's issues, racial identity, and life transitions. E-Mail: drtamarawalden@gmail.com

\section{ORCID ID:}

Christine Rae Platt, https://orcid.org/0000-0002-9122-942X

Melissa Goates-Jones, https://orcid.org/0000-0002-4801-671X

Ramona Maile Cutri, https://orcid.org/0000-0002-4155-7898

Louise Fidalgo Wheeler, https://orcid.org/0000-0001-6680-4915

Tamara Walden, https://orcid.org/0000-0003-2774-2103

Manuscript received January 1, 2022

Final revision received January 16, 2022

Accepted January 20, 2022 